\title{
Identification of defence-related genes expressed in coffee and citrus during infection by Xylella fastidiosa
}

\author{
Marcelo F. Carazzolle • Fernanda R. Rabello • Natália F. Martins • \\ Alessandra A. de Souza • Alexandre M. do Amaral - Juliana Freitas-Astua • \\ Gonçalo A. G. Pereira • Marcos A. Machado • Angela Mehta
}

Accepted: 10 March 2011

(C) KNPV 2011

\begin{abstract}
One of the phytosanitary problems of coffee cultivation in Brazil is Coffee Leaf Scorch (CLS) disease, caused by the phytopathogenic bacterium Xylella fastidiosa. Due to the economic importance of coffee to Brazil and the losses caused by $X$. fastidiosa, a cDNA library (RX1) was constructed using infected coffee stems. This library is one of the 37 coffee EST libraries constructed using different organs and tissues and biological conditions (Coffee Genome ProjectCafEST). The objective of this study was to identify
\end{abstract}

Electronic supplementary material The online version of this article (doi:10.1007/s10658-011-9775-5) contains

supplementary material, which is available to authorized users.

M. F. Carazzolle $\cdot$ G. A. G. Pereira

Laboratório de Genômica e Expressão,

Departamento de Genética e Evolução,

Instituto de Biologia, Universidade Estadual de Campinas,

CP 6109, CEP 13083-970 Campinas, SP, Brazil

M. F. Carazzolle

Centro Nacional de Processamento de Alto Desempenho

em São Paulo, Universidade Estadual de Campinas,

CP 6141, CEP 13083-970 Campinas, SP, Brazil

F. R. Rabello

Universidade de Brasília - UnB,

Brasília, DF, Brazil

N. F. Martins · A. M. do Amaral • A. Mehta

Embrapa Recursos Genéticos e Biotecnologia,

CENARGEN,

PqEB, Av W/5 Final,

CEP 70770-900 Brasília, DF, Brazil genes potentially involved in defence processes in response to $X$. fastidiosa infection by in silico analysis of the transcripts from the RX1 library as well as compare the coffee ESTs to citrus Xylella-infected ESTs. Clustering analysis of the RX1 library grouped a total of 7,501 sequences into 3,248 contigs, 19 of which were not found in the other 36 libraries. Additionally, 119 contigs were considered differentially expressed in comparison with the other libraries and according to statistical criteria. The global analysis
J. Freitas-Astua

Embrapa Mandioca e Fruticultura Tropical, Cruz das Almas, BA, Brazil 
of these contigs showed several genes involved in dehydration and photosynthesis. A total of 2,235 singlets were also obtained in the RX1 library and several of these genes are classically involved in defence processes. The comparison to a Xylellainfected citrus EST library revealed several genes similarly modulated in both species, indicating common defence mechanisms in both host plants in response to $X$. fastidiosa. The results obtained showed that water deprivation and response to osmotic and oxidative stress were expressed in a similar way in both coffee and citrus libraries. This is the first study to propose a common mechanism shared by citrus and coffee plants in response to the same pathogen.

Keywords Coffee leaf scorch · Citrus variegated chlorosis $\cdot$ EST $\cdot$ Defense $\cdot$ cDNA library

\section{Introduction}

Coffee production in Brazil integrates an important agricultural and industrial complex and has a high impact in the economy. Vietnam, Colombia and Brazil represent $50 \%$ of the world coffee production, and Brazil alone is responsible for one third of the production and exportation (Vieira et al. 2006; Mondego et al. 2011).

Coffee production is concentrated in several states in Brazil, including Minas Gerais, Espírito Santo, São Paulo, Paraná, Roraima, and Bahia; Minas Gerais is the main producer and responsible for approximately $50 \%$ of the Brazilian production (Milhomem and Teixeira 2001). One of the problems affecting coffee cultivation in Brazil is Coffee Leaf Scorch (CLS), caused by the bacterium Xylella fastidiosa (Paradela Filho et al. 1995). The first occurrence of $X$. fastidiosa in coffee (Coffea arabica L.) was reported in the cultivar Mundo Novo in the state of São Paulo in 1995 (Paradela Filho et al. 1995). Infected coffee plants typically present stems with short internodes, chlorotic leaves, which are usually small and deformed, leaf abscission and dry branches (Paradela Filho et al. 1995; Lima et al. 1996). The presence of the bacterium in coffee plants has been reported in several coffee-producing regions such as São Paulo, Minas Gerais, Paraná, Espírito Santo and Bahia (Paradela Filho et al. 1995;
Lima et al. 1996; Ueno and Leite 1996); these reports have been restricted to cultivars of $C$. arabica. As well as in Brazil, the disease has been reported in Costa Rica, an important coffee producer in the world (Montero-Astua et al. 2008).

$X$. fastidiosa is a Gram-negative phytopathogenic bacterium that forms aggregates in the xylem of the host plant, blocking the passage of water and nutrients, which is associated with the reduction of the size of leaves and fruits. In severe cases, the bacterium can cause branch dieback (Matiello et al. 1998). Although it has been proposed that polyssaccharides and extracellular enzymes may play an important role in the colonization of the xylem vessels (Simpson et al. 2000), the pathogenicity mechanisms of $X$. fastidiosa are not yet well understood and the characterization of the the plant-pathogen interaction is still at an early stage.

$X$. fastidiosa is also associated with Citrus Variegated Chlorosis (CVC) (Rossetti et al. 1990), one of the most important citrus diseases in Brazil, causing severe losses in citrus production. The bacterium causes chlorosis in the leaves and significant reduction in the size and quality of the fruits, which cannot be used for consumption or for production of concentrated juice (De Negri 1990).

Recently, the Coffee Genome Project (CafESThttp://www.lge.ibi.unicamp.br/cafe) and Citrus Genome Project (CitEST- http://citest.centrodecitricultura.br) were finalized and several cDNA libraries of coffee (Vieira et al. 2006; Mondego et al. 2011) and citrus (Targon et al. 2007) were constructed using different tissues and biological conditions. In this study, we explore the coffee cDNA library constructed from Xylella-infected stems and also perform a comparative analysis to a Xylella-infected citrus cDNA library. We show that several genes are commonly expressed in both perennial host plants and propose similar plantpathogen interaction mechanisms. This is the first study to describe a common mechanism shared by citrus and coffee plants in response to the same pathogen.

\section{Materials and methods}

cDNA libraries of coffee and citrus

For the construction of the coffee EST library, stems were collected from naturally infected coffee plants 
(C. arabica cv. Catuaí vermelho) showing typical CLS symptoms, such as stems with short internodes, dry branches and leaf scorch, at Instituto Agronômico de Campinas, Campinas, Brazil. RNA was extracted using Trizol Reagent (Invitrogen) after confirming the presence of the bacterium by PCR analysis. The mRNA was further isolated by using the kit PolyATract mRNA Isolation Systems (Promega, USA). cDNA synthesis and library construction were performed with the SuperscriptTM Plasmid System with GatewayTM Technology for cDNA Synthesis and Cloning (Invitrogen). The sequencing reactions were performed in an ABI Prism 3700 DNA Analyser (Applied Biosystems Inc., USA).

For the citrus EST library construction, orange plants of the variety Pêra Doce [C. sinensis (L.) Osbeck] were inoculated using a total volume of $40 \mu \mathrm{l}$ of the bacterial suspension $\left(10^{8}\right.$ colony forming units per ml) applied as a drop on the main shoot of citrus plant. Spots were pierced where the drops had been deposited with a syringe needle, until the plant tissue absorbed all the suspension. Leaves presenting CVC symptoms (chlorosis) were collected and used for RNA extraction with Trizol Reagent (Invitrogen). Poly A+ RNA was isolated from $0.5 \mathrm{mg}$ of total RNA using the mRNA Isolation System (Promega Corporation, Madison, WI). cDNA libraries were constructed with the SuperScript Plasmid System with Gateway Technology for cDNA Synthesis and Cloning kit (Invitrogen). Sequencing was performed in ABI 3700 and 3730 DNA Analyzers (Applied Biosystems).

In silico analysis of the coffee and citrus ESTs

A total of 5,483 clusters $(3,248$ contigs and 2,235 singlets) from the RX1 library (Xylella-infected stems) and 14,886 contigs representing all unique contigs of the CafEST Project (transcriptome) were used in this study. Primarily, the RX1 contigs, RX1 singlets and transcriptome were classified using second level Gene Ontology (GO) categories (Ashburner et al. 2000). The GO classification was based on blast best hit, using BLASTx (Altschul et al. 1997) with $e$-value threshold of 1e-10, against the GO protein database. The Gene Ontology classification is a powerful tool to identify common functions shared by genes grouping into GO categories. The hypergeometric test (Martin et al. 2004) and a cut-off of 0.05 ( $95 \%$ confidence rate) was applied to determinate the over-represented GO categories through comparison between categories formed by RX1 contigs or RX1 singlets against categories formed by the transcriptome. The null hypothesis in this test assumes that the number of genes in a particular GO category is distributed as a random variable. This methodology can summarize the total number of expressed genes in the RX1 library, identifying GO categories that are enriched by $\mathrm{RX} 1$ contigs or RX1 singlets in relation to the transcriptome.

The other approach to study the expressed genes in the RX1 library was performed by identifying differentially expressed genes in this library when compared to the transcriptome. This approach uses the ratio between the number of RX1 ESTs and total number of ESTs assembled into a contig (RX1 ESTs/ total ESTs) to infer the relative level of expression of a gene (Okubo et al. 1992). The AC test (Audic and Claverie 1997) and a cut-off of 0.05 (95\% confidence rate) was applied to identify relative frequencies of RX1 ESTs into RX1 contigs that were overrepresented (up regulated) or sub-represented (down regulated). The null hypothesis in this test assumes the same relative frequency of ESTs in all of the coffee libraries. These differentially expressed genes and transcriptome were classified using third level Gene Ontology categories. The over-represented GO categories of differentially expressed genes in relation to the transcriptome were calculated using the hypergeometric test (Martin et al. 2004) with a cut-off of 0.05 . In this case the analysis resulted in GO categories that were enriched by differentially expressed genes. This methodology was also applied in other recent analyses (Han et al. 2006; D'Souza et al. 2008; Murray et al. 2007).

Concomitantly, in order to identify orthologous genes between coffee and citrus related to infection, the RX1 clusters were also compared to 6,495 citrus ESTs from the cDNA library CS-101, constructed using $X$. fastidiosa-infected leaves (Targon et al. 2007), with the tBLASTx algorithm (Altschul et al. 1997) and an $e$-value threshold of 1e-10. This methodology generated a list of coffee genes that are expressed in both species. Using the same methods, these genes were grouped into the third level GO categories and compared with the GO categories of the transcriptome. 


\section{Results and discussion}

\section{RX1 library characterization}

The Coffee Genome Project (CafEST) generated a total of 130000 valid EST sequences collected from 37 cDNA libraries, constructed from a number of tissues and organs and under a range of conditions, representing 39,312 unigenes (14,886 contigs and 24,426 singlets) (Vieira et al. 2006). During the development of the CafEST project, priority was given to libraries constructed using stressed conditions (biotic or abiotic) and therefore only one library (SS1) was constructed using healthy tissues (pooled leaves and stems). In this study, we investigated the group of ESTs produced during the biotic stress induced by the CLS disease (RX1 library). A total of 7,501 ESTs were obtained from this library, which were grouped into 5,483 clusters, including 3,248 contigs and 2,235 singlets. After GO annotation, a total of $76 \%$ of coffee sequences could be associated with one or more GO categories. The association using second level GO categories resulted in 145 categories for the transcriptome and 120 categories for the RX1 library (contigs and singlets). In order to identify the GO categories enriched by expressed genes from the RX1 library in relation to the transcriptome, we performed a comparison using a hypergeometric test (Martin et al. 2004) and a cut-off of 0.05 ( $95 \%$ of confidence rate), resulting in 27 overrepresented second level GO categories.

A global analysis of the RX1 library (Fig. 1) showed that most genes (approximately 55\%) of the RX1 library are involved in cellular and primary metabolic processes. An over-representation of genes involved in catabolic processes, response to abiotic stimulus, and photosynthesis could be observed when analyzing the contigs; while genes related to defence response and response to endogenous stimulus could be observed when analyzing the singlets. Indeed several of these singlets represented genes potentially involved in defense mechanisms (Table 1), and are discussed below.

Genes uniquely detected in Xylella-infected coffee library

In this study, two distinct peroxidase transcripts were present only in the Xylella-infected coffee library and were represented as two singlets (Table 1). One of them presented similarity with a soybean peroxidase that occurs in root, stems, leaves, and seed pods regardless of any stress stimulus (Chen and Vierling 2000), while the other presented similarity with a novel thylakoid lumen peroxidase apparently without function on defence to biotic stress (Kieselbach et al. 2000). However, the presence of these transcripts solely in the RX1 library may be associated with the response to $X$. fastidiosa infection. Guidetti-Gonzalez et al. (2007), analyzing the peroxidases from 33 citrus EST libraries, showed that some of them are constitutive, while others are induced by various stimuli. Interestingly, some of the contigs harboring peroxidase transcripts were composed by reads made solely from a library constructed from Xylellainfected citrus plants, indicating that they may be involved in the response of citrus to this pathogen.

One singlet with similarity to NADPH oxidoreductase homolog was also found in the CLS library (Table 1). Along with peroxidases, NADPH oxidoreductases are major sources for reactive oxygen species (ROS) production as defence mechanisms during biotic stresses (Melillo et al. 2006), and these transcripts may play such a role in this compatible interaction between coffee and $X$. fastidiosa.

A transcript of glutathione S-transferase (GST), involved in the detoxification of lipid peroxidation products, was also found in the CLS library (Table 1). This gene protects cells from ROS and damage from stress conditions (Chen et al. 2004) and is often found in high copy number/isoforms in plants.

A group of ESTs encoding lipoxygenases (LOXes) was also observed among the RX1 singlets. LOXes constitute a large gene family of fatty acid dioxygenases that are ubiquitous in plants and animals. They produce hydroperoxides that are converted into compounds involved in a variety of physiological processes such as plant development and biotic and abiotic stress adaptation (Liavonchanka and Feussnerm 2006). Although there are reports of increased LOX expression in compatible interactions (disease), it is more commonly associated with incompatible interactions, where it plays an important role in disease resistance, as observed in Citrus reticulata (a resistant citrus genotype) inoculated with $X$. fastidiosa (HR) (Guidetti-Gonzalez et al. 2007).

Another gene found in the CLS library codes for a disease resistance-responsive protein. This protein is 
Fig. 1 Gene function association using second level Gene Ontology (GO) categories at the biological process level. The percentage of genes refers to the RX1 contigs, RX1 singlets and transcriptome that match the GO categories. The GO categories displayed were selected based on statistical criteria using the transcriptome as reference

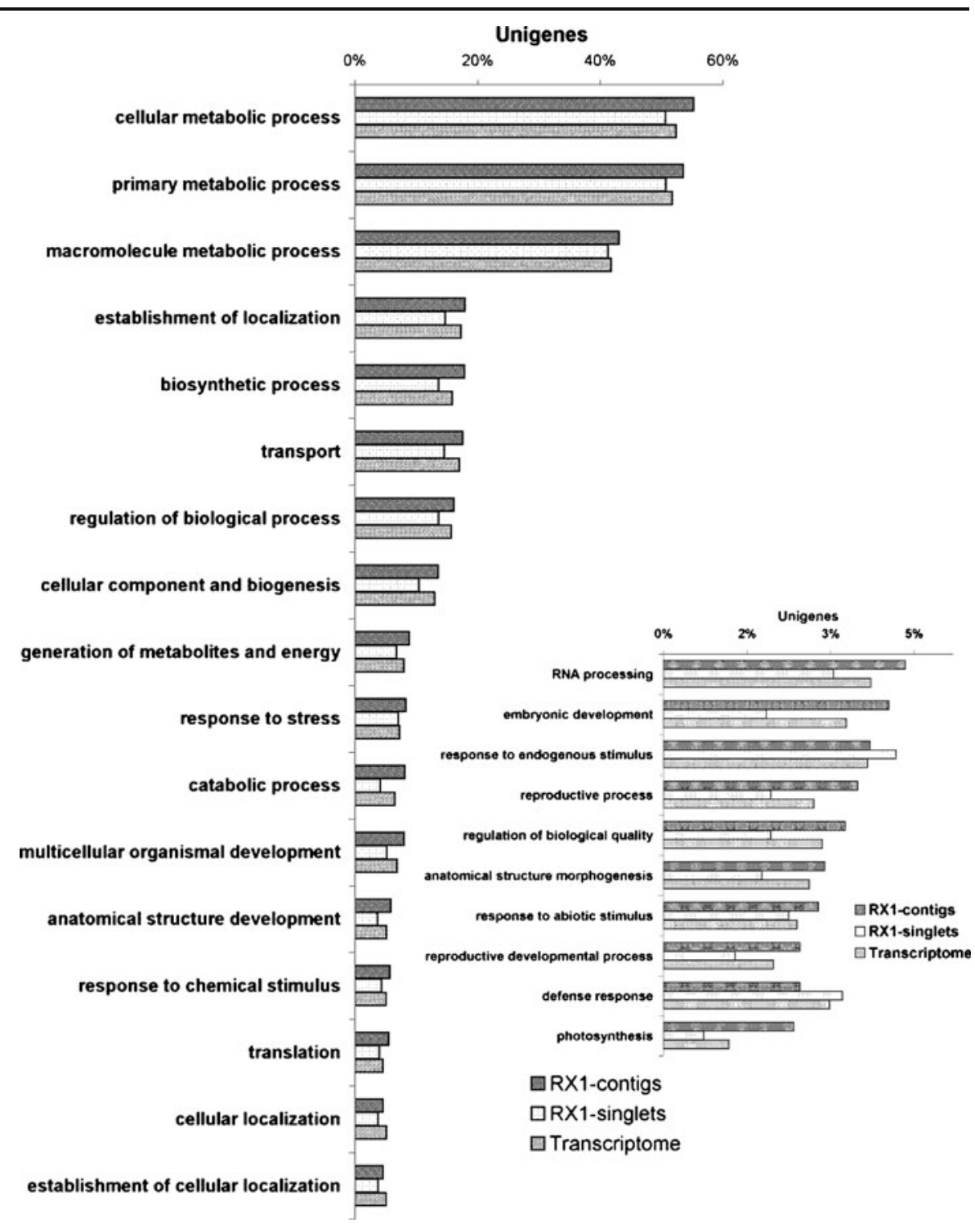

involved in lignin biosynthesis and may have a role in biotic and abiotic stress resistance through the increase in lignin production, but there are no studies on this protein in coffee plants.

Finally, the BlastX of three singlets from the coffee Xylella-infected library presented hits with similarity to disease resistance proteins; all of them encoded by resistance $(R)$ genes of the NBS-LRR cluster. R proteins act as direct or indirect receptors of pathogen effectors, or sensors that detect cell alterations caused by these effectors. After the initial recognition, a downstream signal transduction cascade leads to defence mechanisms, often a hypersensitive response, that may restrict the pathogen in its original site of infection (Jones and Dangl 2006). Among the $R$ genes, are the well-studied NBS-LRR cluster that includes Topovirus resistance gene homologues SW5, a nematode resistance protein Mi-1.2, a Pseudomonas syringae resistance gene PRF, and the Globodera rostochiensis resistance genes Hero and Gpa-2 (Rehman et al. 2009). Since the object of this study is a compatible interaction (when disease occurs), these singlets may represent resistance gene analogs (RGA) that are not fully functional in $C$. arabica. Alternatively, as suggested for the G. rostochiensistomato interaction, one of two situations might be 
Table 1 Singlets expressed in coffee stems infected by $X$. fastidiosa, putatively involved in the defence response

\begin{tabular}{|c|c|c|c|}
\hline Encoded protein & Homologous organism & Accession number & $e$-value \\
\hline Expressed protein & A. thaliana & gi| $18395895 \mid$ & $3 e-48$ \\
\hline Putative heat shock protein & A. thaliana & gi| $15242707 \mid$ & 0,002 \\
\hline Putative glutathione S-transferase & O. sativa & gi| $24796806 \mid$ & $4 e-45$ \\
\hline Elongation factor $\mathrm{Tu}$ family protein & A thaliana & gi| $15221423 \mid$ & $5 e-17$ \\
\hline Proline-rich protein family & A. thaliana & gi| $15219860 \mid$ & $1 \mathrm{e}-06$ \\
\hline NADPH oxidoreductase homolog & C. arietinum & gi| 4958922| & $8 \mathrm{e}-16$ \\
\hline Heat shock cognate $70 \mathrm{kDa}$ protein & Malus $x$ domestica & gi| $6969976 \mid$ & $7 e-91$ \\
\hline Malate dehydrogenase (oxaloacetate- decarboxilating) (NADP) & L. esculentum & gi| 7431232| & $3 e-54$ \\
\hline Heat shock protein cognate 70 & O. Sativa & gi| $29124135 \mid$ & $1 \mathrm{e}-17$ \\
\hline ATP synthase beta chain, mitochondrial precursor & $N$. plumbaginifolia & gi| $114421 \mid$ & $5 \mathrm{e}-18$ \\
\hline Tryptophan synthase alpha chain & A. thaliana & gi| $21593559 \mid$ & $3 e-62$ \\
\hline Thioredoxin H-type & A thaliana & gi| $15231958 \mid$ & $3 e-22$ \\
\hline Endochitinase & O. Sativa & gi| 47497287| & $8 \mathrm{e}-52$ \\
\hline Tospovirus resistance protein $\mathrm{D}$ & L. esculentum & gi| $15418713 \mid$ & $3 e-49$ \\
\hline Putative late blight resistance protein & S. demissum & gi| $48057663 \mid$ & $6 e-43$ \\
\hline Putative disease resistance protein & S. demissum & gi| 47900744| & $1 \mathrm{e}-31$ \\
\hline Copper methylamine oxidase precursor & A. thaliana & gi| $30689034 \mid$ & $2 \mathrm{e}-76$ \\
\hline Latex-abundant family protein/caspase family protein & A. thaliana & gi| $30678252 \mid$ & $4 \mathrm{e}-59$ \\
\hline Alternative oxidase1a, mitochondrial [precursor] & P. tremula $\times$ P. tremuloides & gi| 6967043| & $2 \mathrm{e}-39$ \\
\hline Putative ascorbate peroxidase (TL29) & L. esculentum & gi| $11387206 \mid$ & $1 \mathrm{e}-48$ \\
\hline Peroxidase & G. $\max$ & gi| 4204763| & $1 \mathrm{e}-91$ \\
\hline Lipoxygenase & S. tuberosum & gi| $7433144 \mid$ & $3 e-67$ \\
\hline Disease resistance-responsive protein-related/dirigent protein & A. thaliana & gi| $15239779 \mid$ & $8 \mathrm{e}-32$ \\
\hline DNA-damage-repair/toleration protein & A. thaliana & gi| $21536600 \mid$ & $5 e-97$ \\
\hline
\end{tabular}

taking place: either the putative $R$ genes do not properly activate disease resistance signaling, or they may interact with a pathogen effector that modulates host defence responses (Rehman et al. 2009).

Even though several genes involved in defence response to pathogens were found to be over represented in the CLS library, it should be noted that the coffee cultivar studied is susceptible to $X$. fastidiosa and the library was constructed from symptomatic coffee stems. Hence, it is very likely that these genes, although differentially expressed when compared to the healthy coffee libraries, have peripheral role in avoiding infection and disease, either because they are triggered with a significant delay in time or because they represent a secondary response due to the physiological effect caused by the infection, as proposed by De Souza et al. (2007a) when studying the compatible citrus-Xylella interaction.
Comparison of the differentially expressed genes from the RX1 library to the CafEST transcriptome

In order to improve the level of information regarding genes expressed during the infection phase, the analysis of differentially expressed genes (up and down regulated) using $\mathrm{AC}$ test (Audic and Claverie 1997) and a cut-off of 0.05 (95\% of confidence rate) was applied to the $3,248 \mathrm{RX} 1$ contigs. This methodology identified 119 differentially expressed contigs (Supplemental Table 1), which represented $4.6 \%$ of all the RX1 contigs. These genes were grouped according to the third level of GO category (Fig 2) resulting in 380 categories. Also the transcriptome was submitted to the third level of GO annotation resulting in 700 categories. The hypergeometric test and a cut-off of 0.05 resulted in 26 over-represented third level GO categories. 


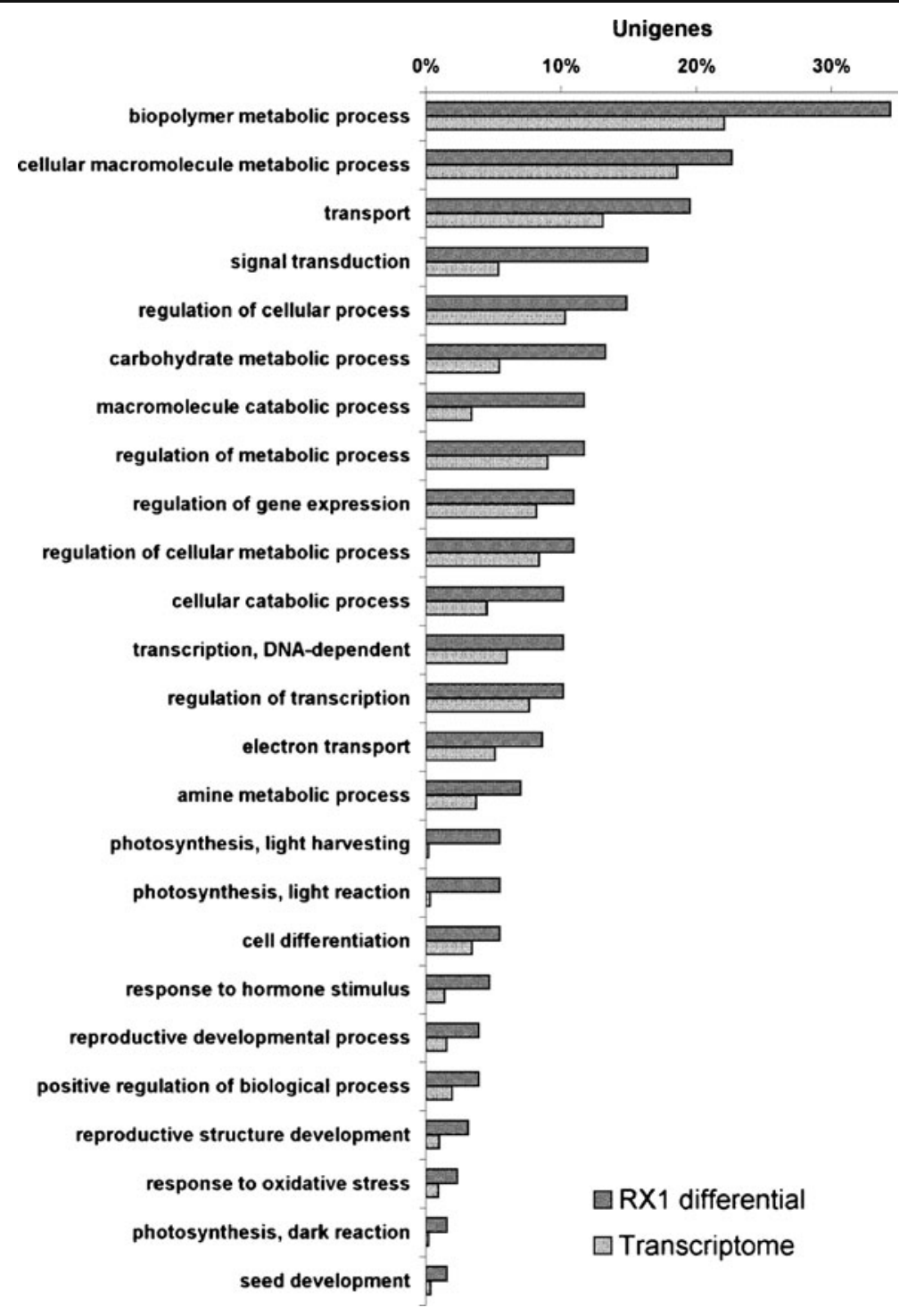

Fig. 2 Gene function association using third level Gene Ontology (GO) categories at the biological process level. The percentage of genes is related to the transcriptome and differentially expressed genes (up- and down-regulated) in $\mathrm{RX} 1$ contigs that match the GO categories. The over-represented

Interestingly, a large group of down-regulated ESTs were obtained and were constituted by genes from the GO category of photosynthesis (Fig. 2). Transcriptional down-regulation of photosynthesisrelated genes has been reported previously during compatible interactions between host plants and their pathogens (Restrepo et al. 2005; Moy et al. 2004), including bacteria (Biemelt and Sonnewald 2006; Bonfig et al. 2006; Balaji et al. 2007).
GO categories displayed were selected based on statistical criteria using the transcriptome as reference. The photosynthesis light harvesting and photosynthesis light reaction categories are constituted by down-regulated genes

Photosynthesis is a common mechanism affected during infection (Kong et al. 2007), and a very striking transcriptional down-regulation of photosynthesis ESTs was observed in our investigation, which is in agreement with other studies that analyzed the expression of genes during fungal infection of plants in compatible and incompatible interactions (Gibly et al. 2004; Espinoza et al. 2007; Fung et al. 2008). Scholes et al. (1994) suggest that the high 
concentration of carbohydrates, resulting from the increase in invertase activity caused by fungal infection, causes directly or indirectly a gradual down-regulation of the Calvin cycle leading to the inhibition of photosynthesis.

The analysis between the RX1 library and the coffee transcriptome also revealed a total of 19 contigs, which were present only in the RX1 library and again included a NBS-LRR disease resistance protein homologue, as well as proteins with unknown function (expressed proteins and no hits). NBS-LRR disease resistance proteins act in multi-protein complexes mediating the interaction with pathogen effectors. Resistance genes ( $\mathrm{R}$ genes) in plants are abundant and may represent more than $1 \%$ of all the genes where their diversity is critical for the recognition and response to the attack from diverse pathogens. Despite their prevalence in the genome, little is known about the expression of these genes in coffee during plant-pathogen interactions. They revealed that the majority of NBS-LRR transcripts were present at low levels in unchallenged plants and many showed tissue specific expression. Further studies need to be performed in coffee in order to verify the specific role played by these genes in the defense process.

Another contig present only in the RX1 library was the respiratory burst oxidase protein $\mathrm{E}$, which is encoded by the gene RBOHE in Arabidopsis. The protein function is related to calcium-dependent NADPH oxidase, generating superoxide in a multi-pass membrane protein. The NADPH oxidases (NOX) catalyze the production of superoxides, a type of reactive oxygen species (ROS) conserved in plant and animal kingdoms. The enzymatic products are associated with direct oxidative cross-linking of cell wall components during defence and differentiation of vascular tissue in plants (Sagi and Fluhr 2006). The antioxidant pathway regulates the appropriate induction of acclimation processes or execution of cell death programs (Shao et al. 2008).

Far-red impaired responsive protein was also observed only in the RX1 library and was identified as one of the shade-avoidance players in shade-avoidance responses. Coupland and Prat Monguio (2005) reported the identification of the photoreceptors and light signalling molecules and indicate that, despite the unknown mechanism, those receptors affect plants, both as an environmental stress and as a developmental signal.
The comparison of the RX1 library to the CafEST transcriptome also revealed genes up-regulated in the RX1 library such as chitinases, dehydration genes, aquaporins and transcription factors. These are well known genes involved in several biotic and abiotic stresses. The up-regulation of dehydration genes and aquaporins was expected, since blockage of plant xylem vessels occurs during $X$. fastidiosa infection. Interestingly, these genes were also observed in a Xylella-infected citrus library and are discussed below.

The results obtained from this comparison show that several genes were differentially expressed in the RX1 library when compared to all the other 36 coffee libraries in different conditions, including biotic and abiotic stresses. A comparison to a library constructed from non-infected stems would be ideal and would give more direct clues as to which genes are specifically involved in the response to $X$. fastidiosa. Although the SS1 library was constructed including stems as well as leaves, differentially expressed genes were observed when this library was compared to the $\mathrm{RX} 1$. It is possible that these genes are indeed related to $X$. fastidiosa infection.

\section{Comparison of Xylella-infected coffee and citrus ESTs}

The RX1 library was also compared to a Xylellainfected citrus library (CS-101). A total of 2,112 coffee ESTs showed a tBLASTx hit in the citrus library, indicating the expression of several genes in both plants (Fig. 3). As mentioned above, upregulated genes involved in water deprivation and response to osmotic and oxidative stress were expressed in a similar way in both libraries (Supplemental Table 1).

Plants express a large number of isoenzymes modulated by signals related to cellular detoxification of reactive oxygen species, which may accumulate for different reasons, including wounding or pathogen attack (Dietz et al. 2006). The results obtained in this study indicate that the effect of water blockage caused by $X$. fastidiosa may trigger the same kind of stress in coffee and citrus plants, although the symptoms are quite different. Cross inoculation studies with coffee and citrus $X$. fastidiosa strains in both host plants are still controversial. Although Li et al. (2001) showed that CLS can be caused by coffee and citrus strains, 


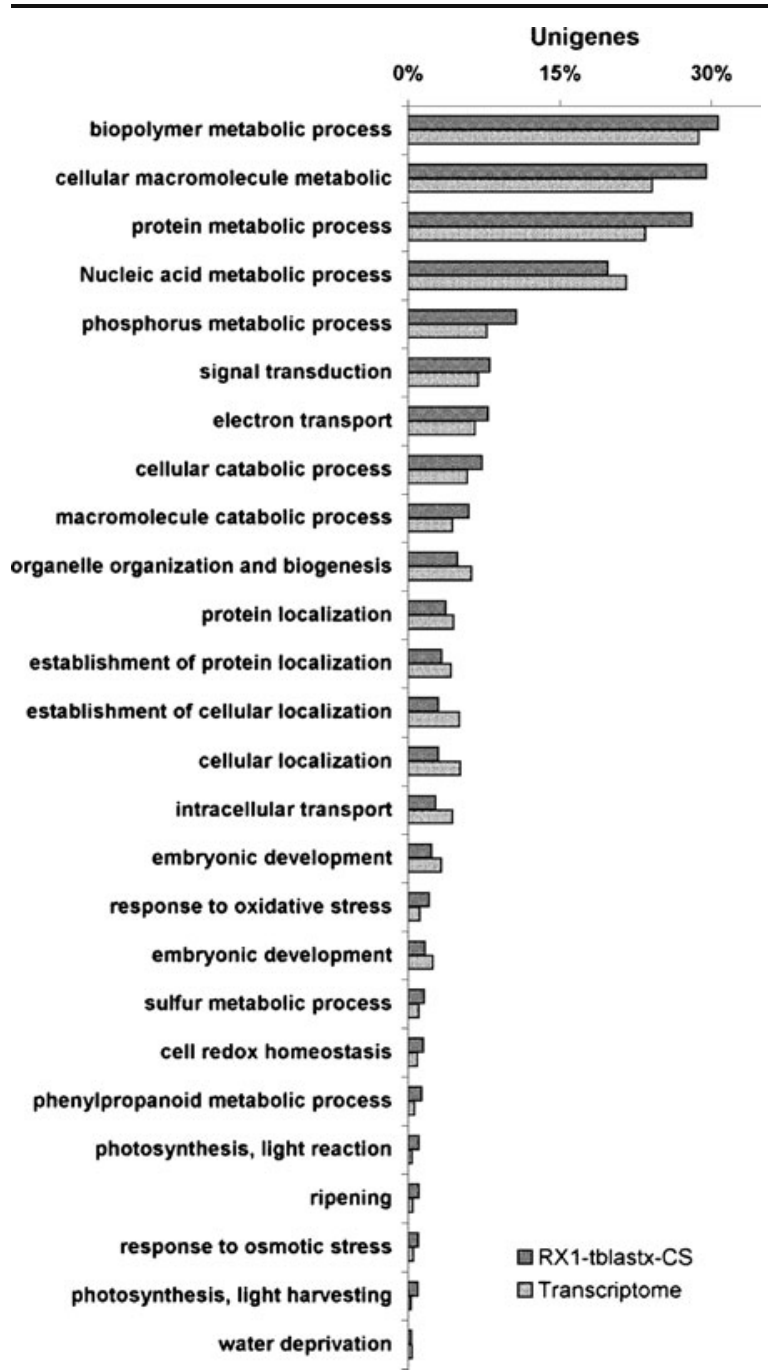

Fig. 3 Gene function association using third level Gene ontology (GO) categories at the biological process level. The percentage of genes is related to coffee genes (expressed in RX1 and citrus libraries), and the transcriptome that match with the GO categories. The GO categories displayed were selected based on statistical criteria using the transcriptome as reference

Almeida et al. (2008), in a recent work, suggest that CVC and CLS are caused by two biologically distinct $X$. fastidiosa strains. These results indicate that this issue is still not well defined, although there may be similarities in the pathogenicity mechanisms.

Among the genes associated with water stress identified in both libraries are the osmotic stress induced gene, aquaporin and the dehydration responsive element binding protein. Aquaporins are found in membrane cells of all living organisms, including fungi, bacteria, plants and animals (Tyerman et al.
2002) and enable the passive diffusion of water through the membrane cells, increasing the osmotic conductivity of the membrane (Preston et al. 1992; Siefritz et al. 2002). It is well known that water stress has a high influence on the expression of aquaporin (Baiges et al. 2002). The induction of this gene is related to the increase in membrane permeability to water transportation under water deficit conditions (Yamada et al. 1997).

The up-regulation of the gene that encodes the dehydration responsive element binding protein could be related to a typical response to drought observed in plants with CVC and CLS. As observed in plants with CVC symptoms (De Souza et al. 2007a), this protein was shown to be induced by ABA (Abe et al. 1997). Synthesis of ABA is not a feature of plants with CVC (Gomes et al. 2003) and therefore the physiological conditions are different. However, this protein seems to respond to different stimuli and protect the plant in adverse conditions (Abe et al. 1997). In general, the up-regulation of these genes in citrus and coffee could be associated with water stress suppression by the plant in response to xylem vessels blockage caused by X. fastidiosa.

Others groups of up-regulated genes in coffee were also observed, when compared to the citrus ESTs. Among these genes were several chitinases, DnaJ-like protein, and several proteins with unknown function. Chitinases catalyze the hydrolysis of chitin oligomers and are generally induced in response to fungal pathogens or abiotic stress, or during plant development (Collinge et al. 1993). DnaJ is a chaperone that functions in protein folding and marks incorrectly folded proteins for turnover (Bohnert et al. 1995). Despite the increase in their expression that occurs during the abiotic stresses, induction in the synthesis of chaperones has also been observed in response to pathogen attack (Jelitto-Van Dooren et al. 1999). In $C$. sinensis with CVC, DnaJ induction was not observed (De Souza et al. 2007a), however, up-regulation was observed in C. reticulata (resistant to CVC) inoculated with $X$. fastidiosa (De Souza et al. 2007b) and it was associated with defence-response. These results suggest that in spite of the similarities between the host-response to $X$. fastidiosa, different behaviours could be characteristic from each host plant.

Among the down-regulated genes observed when compared to the citrus clusters were genes involved in photossynthesis, although the transcripts related to 
photosynthesis were also down-regulated in plants with CVC when compared to healthy tissues (De Souza et al. 2007a). The down-regulation of these photosynthesis-associated genes is perhaps a consequence of disorders that occur in the photosynthetic apparatus of CVC and CLS symptomatic plants.

Another interesting result obtained was that among the 19 contigs present only in the RX1 library when compared with the entire transcriptome of coffee, 5 contigs [contig4963 (hypothetical protein), contig4787 (2-hydroxy-acid oxidase, peroxisomal), contig4730 (Glyceraldehyde-3-phosphate dehydrogenase B), contig4612 (copia protein) and contig4458 (FAD-binding domain-containing protein)] were also observed in the citrus library, indicating that these genes may be expressed in response to the same stimulus. Most of them are related to energy conversion and production.

\section{Conclusions}

Overall, in this study, we have characterized a Xylellainfected coffee library and shown the presence of several genes involved in the response to biotic stress as well as water deprivation conditions. The comparison with the citrus Xylella-infected library revealed several commonly expressed genes, including $60 \%$ of differentially expressed genes previously identified and genes associated with water stress conditions. When the RX1 singlets presented in Table 1 were checked against citrus ESTs, 15 genes showed a positive match, which represents a percentage of approximately $60 \%$. Although different tissues from coffee and citrus were used for comparison, the results obtained in this study indicate that similar defence mechanisms may be triggered in coffee and citrus in response to $X$. fastidiosa infection. We could clearly observe several genes commonly expressed in infected coffee and citrus and the main GO categories found were water deprivation, response to osmotic stress, response to oxidative stress, signal transduction and cellular catabolic processes. These genes were up-regulated in both $X$. fastidiosa infected hosts when compared to the entire coffee transcriptome and therefore represent interesting candidates for future studies aiming at a better comprehension of $X$. fastidiosa-host interactions. Another interesting result obtained was that several genes involved in regulation were observed in the RX1 library but not in citrus; such as genes associated to regulation of cellular process, regulation of metabolic process, regulation of gene expression, regulation of cellular metabolic process, regulation of transcription and regulation of biological process. These genes need to be further investigated in order to verify their specific role in the $X$. fastidiosa response. This is the first study to propose a common mechanism shared by citrus and coffee plants during response to the same pathogen infection. In this work we present an overview of the gene expression in both hosts infected with the same pathogen. Additional studies need to be performed to better investigate the similarities and differences found in order to propose a more detailed plant defence mechanism in response to this important pathogen.

\section{References}

Abe, H., Yamaguchi-Shinozaki, K., Urao, T., Iwasaki, T., Hosokawa, D., \& Shinozaki, K. (1997). Role of Arabidopsis MYC and MYB homologs in drought-and abscisic acid-regulated gene expression. The Plant Cell, 9, 1859-1868.

Almeida, R. P., Nascimento, F. E., Chau, J., Prado, S. S., Tsai, C. W., Lopes, S. A., et al. (2008). Genetic structure and biology of Xylella fastidiosa strains causing disease in citrus and coffee in Brazil. Applied and Environmental Microbiology, 74, 3690-3701.

Altschul, S., Madden, T., Schaffer, A., Zhang, J., Zhang, Z., Mille, W., et al. (1997). Gapped BLAST and PSI-BLAST, A new generation of protein database search programs. Nucleic Acids Research, 25, 3389-3402.

Ashburner, M., Ball, C. A., Blake, J. A., Botstein, D., Butler, H., Cherry, J. M., et al. (2000). Gene Ontology, tool for the unification of biology. Nature Genetics, 25, 25-29.

Audic, S., \& Claverie, J. M. (1997). The significance of digital gene expression profiles. Genome Research, 7, 986-995.

Baiges, I., Schaffner, A. R., Affenzeller, M. J., \& Mas, A. (2002). Plant aquaporins. Plant Physiology, 115, 175-182.

Balaji, V., Gibly, A., Debbie, P., \& Sessa, G. (2007). Transcriptional analysis of the tomato resistance response triggered by recognition of the Xanthomonas type III effector AvrXv3. Functional \& Integrative Genomics, 4, 305-316.

Biemelt, S., \& Sonnewald, U. (2006). Plant-microbe interactions to probe regulation of plant carbon metabolism. Journal of Plant Physiology, 163, 307-318.

Bohnert, H. J., Nelson, D. E., \& Jensen, R. G. (1995). Adaptations to environmental stresses. The Plant Cell, 7, 1099-1111.

Bonfig, K. B., Schreiber, U., Gabler, A., Roitsch, T., \& Berger, S. (2006). Infection with virulent and avirulent $P$. syringae 
strains differentially affects photosynthesis and sink metabolism in Arabidopsis leaves. Planta, 225, 1-12.

Chen, H., \& Vierling, R. A. (2000). Molecular cloning and characterization of soybean peroxidase gene families. Plant Science, 150, 129-137.

Chen, S., Vaghchhipawala, Z., Li, W., Asard, H., \& Dickman, M. B. (2004). Tomato phospholipid hydroperoxide glutathione peroxidase inhibits cell death induced by bax and oxidative stresses in yeast and plants. Plant Physiology, 135, 1630-1641.

Collinge, D. B., Kragh, K. M., Mikkelsen, J. D., Nielsen, K. K., Rasmussen, U., \& Vad, K. (1993). Plant chitinases. The Plant Journal, 3, 31-40.

Coupland, G., \& Prat Monguio, S. (2005). Cell signalling and gene regulation signalling mechanisms in plants, examples from the present and the future. Current Opinion in Plant Biology, 8, 457-461.

D’Souza, C. A., Chopra, V., Varhol, R., Xie, Y. Y., Bohacec, S., Zhao, Y., et al. (2008). Identification of a set of genes showing regionally enriched expression in the mouse brain. BMC Neuroscience, 9, 66-80.

De Negri, J. D. (1990). Clorose variegada dos citros, Nova anomalia afetando pomares em São Paulo e Minas Gerais. Comunicado Técnico $n^{\circ} 82$, CATI Campinas, 6p.

De Souza, A. A., Takita, M. A., Coletta-Filho, H. D., Targon, M. L. P. N., Carlos, F. E., Locali-Fabris, E. C., et al. (2007). Analysis of expressed sequence tags from Citrus sinensis L. Osbeck infected with Xylella fastidiosa. Genetics and Molecular Biology, 30, 957-964.

De Souza, A. A., Takita, M. A., Coletta-Filho, H. D., Campos, M. A., Teixeira, E. C. J., Targon, M. L. P. N., et al. (2007). Comparative analysis of differentially expressed sequence tags of sweet orange and mandarin infected with Xylella fastidiosa. Genetics and Molecular Biology, 30, 965-971.

Dietz, K. J., Jacob, S., Oelze, M. L., Laxa, M., Tognetti, V., de Miranda, S. M., et al. (2006). The function of peroxiredoxins in plant organelle redox metabolism. Journal of Experimental Botany, 57, 1697-1709.

Espinoza, C., Vega, A., Medina, C., Schlauch, K., Cramer, G., \& Arce-Johnson, P. (2007). Gene expression associated with compatible viral diseases in grapevine cultivars. Functional \& Integrative Genomics, 7, 95-110.

Fung, R. W., Gonzalo, M., Fekete, C., Kovacs, L. G., He, Y., Marsh, E., et al. (2008). Powdery mildew induces defense-oriented reprogramming of the transcriptome in a susceptible but not in a resistant grapevine. Plant Physiology, 146, 236-249.

Gibly, A., Bonshtien, A., Balaji, V., Debbie, P., Martin, G. B., \& Sessa, G. (2004). Identification and expression profiling of tomato genes differentially regulated during a resistance response to Xanthomonas campestris pv. vesicatoria. Molecular Plant-Microbe Interactions, 17, 1212-1222.

Gomes, M. M. A., Lagôa, A. M. M. A., Machado, E. C., \& Medina, C. L. (2003). Abscisic acid and indole-3-acetic acid contents in orange trees infected by Xylella fastidiosa and submitted to cycles of water stress. Plant Growth Regulation, 39, 263-270.

Guidetti-Gonzalez, S., Freitas-Astúa, J., do Amaral, A. M., Martins, N. F., Mehta, A., Silva, M. S., et al. (2007). Genes associated with hypersensitive response (HR) in the citrus EST (CitEST) database. Genetics and Molecular Biology, 30, 943-956.

Han, J. Y., Park, T. S., Kim, J. N., Kim, M. A., Lim, D., Lim, J. M., et al. (2006). Gene expression profiling of chicken primordial germ cell ESTs. BMC Genomics, 7, 220-226.

Jelitto-Van Dooren, E. P., Vidal, S., \& Denecke, J. (1999). Anticipating endoplasmic reticulum stress. A novel early response before pathogenesis-related gene induction. Plant Cell, 11, 1935-1944.

Jones, J. D. G., \& Dangl, J. L. (2006). The plant immune system. Nature, 444, 323-329.

Kieselbach, T., Bystedt, M., Hynds, P., Robinson, C., \& Schroder, W. P. (2000). A peroxidase homologue and novel plastocyanin located by proteomics to the Arabidopsis chloroplast thylakoid lumen. FEBS Letters, 480, 271276.

Kong, L., Ohm, H. W., \& Anderson, J. M. (2007). Expression analysis of defense-related genes in wheat in response to infection by Fusarium graminearum. Genome, 50, 10381048.

Li, W. B., Pria, W. D., Teixeira, D. C., Miranda, V. S., Ayres, A. J., Franco, C. F., et al. (2001). Coffee leaf scorch caused by a strain of Xylella fastidiosa from citrus. Plant Disease, $85,501-505$.

Liavonchanka, A., \& Feussnerm, I. (2006). Lipoxygenases, Occurrence, functions and catalysis. Journal of Plant Physiology, 163, 348-357.

Lima, J. E. O., de Miranda, V. S., Coutinho, A., Roberto, S. R., \& Carlos, E. F. (1996). Distribuição de Xylella fastidiosa no cafeeiro nas regiões cafeeiras, e seu isolamento in vitro. Fitopatologia Brasileira, 21, 392-393.

Martin, D., Brun, C., Remy, E., Mouren, P., Thieffry, D., \& Jacq, B. (2004). GOToolBox, functional analysis of gene datasets based on Gene Ontology. Genome Biology, 5, R101.

Matiello, J. B., Miranda, V. S., Almeida, S. R., \& Manfio, G. P. (1998). "Amarelinho" ou requeima das folhas do cafeeiro, conheça e tome cuidado. Boletim Informativo Fund. André Tosello-CTC/Fundecitrus.

Melillo, M. T., Leonetti, P., Bongiovanni, M., CastagnoneSereno, P., \& Bleve-Zacheo, T. (2006). Modulation of reactive oxygen species activities and $\mathrm{H}_{2} \mathrm{O}_{2}$ accumulation during compatible and incompatible tomato-root-knot nematode interactions. The New Phytologist, 170, 501512.

Milhomem, A. V. \& Teixeira, S. M. (2001). Competitividade dos sistemas produtivos de cafés no Brasil. Simpósio Brasileiro de Pesquisa dos Cafés do Brasil (Vitória, ES). Anais. Brasilia, D.F. Embrapa Café (CD-ROM), 21362144.

Mondego, J. M., Vidal, R. O., Carazzolle, M. F., Tokuda, E. K., Parizzi, L. P., Costa, G. G., et al. (2011). An EST-based analysis identifies new genes and reveals distinctive gene expression features of Coffea arabica and Coffea canephora. BMC Plant Biology, 11. doi:10.1186/14712229-11-30.

Montero-Astua, M., Hartung, J. S., Aguilar, E., Chacon, C., Li, W., Albertazzi, F., et al. (2008). Genetic diversity of Xylella fastidiosa isolates from Costa Rica, Sao Paulo and the United States of America. Phytopathology, 97, 13381347. 
Moy, P., Qutob, D., Chapman, B. P., Atkinson, I., \& Gijzen, M. (2004). Patterns of gene expression upon infection of soybean plants by Phytophthora sojae. Molecular PlantMicrobe Interactions, 17, 1051-1062.

Murray, D., Doran, P., MacMathuna, P., \& Moss, A. C. (2007). In silico gene expression analysis - an overview. Molecular Cancer, 6, 50-60.

Okubo, K., Hori, N., Matoba, R., Nuyama, T., Fukushima, A., Kojima, Y., et al. (1992). Large scale cDNA sequencing for analysis of quantitative and qualitative aspects of gene expression. Nature Genetics, 2, 173-179.

Paradela Filho, O., Sugimori, M. H., Ribeiro, I. J. A., Machado, M. A., Laranjeira, F. F., Garcia Júnior, A., et al. (1995). Primeira constatação em cafeeiro no Brasil da Xylella fastidiosa causadora da clorose variegada dos citrus. Laranja, 16, 127-134.

Preston, G. M., Carroll, T. P., Guggino, W. B., \& Agree, P. (1992). Appearance of water channels in Xenopus oocytes expressing red cell CHIP28 protein. Science, 256, 385-387.

Rehman, S., Postma, W., Tytgat, T., Prins, P., Qin, L., Overmars, H., et al. (2009). A secreted SPRY domaincontaining protein (SPRYSEC) from the plant-parasitic nematode Globodera rostochiensis interacts with a CCNB-LRR protein from a susceptible tomato. Molecular Plant-Microbe Interactions, 22, 330-340.

Restrepo, S., Myers, K. L., del Pozo, O., Martin, G. B., Hart, A. L., Buell, C. R., et al. (2005). Gene profiling of a compatible interaction between Phytophthora infestans and Solanum tuberosum suggests a role for carbonic anhydrase. Molecular Plant-Microbe Interactions, 18, 913-922.

Rossetti, V., Garnier, M. B., Bove, J. M., Beretta, M. J. G., Teixeira, A. R. R., Quaggio, J. Á., et al. (1990). Présence de bactéries dans le xyléme d'orangers atteints de chlorose variégée une nouvelle maladie des agrumes au Brésil. Les Comptes Rendus de l'Académie des Sciences Paris, 310, 345-349.
Sagi, M., \& Fluhr, R. (2006). Production of reactive oxygen species by plant NADPH oxidases. Plant Physiology, 141, 336-340.

Scholes, J. D., Lee, P. J., Horton, P., \& Lewis, D. H. (1994). Invertase, understanding changes in the photosynthetic and carbohydrate metabolism of barley leaves with powdery mildew. The New Phytologist, 126, 213-222.

Shao, H. B., Chu, L. Y., Shao, M. A., Jaleel, C. A., \& Mi, H. M. (2008). Higher plant antioxidants and redox signaling under environmental stresses. Comptes Rendus Biologies, $331,433-441$.

Siefritz, F., Tyree, M. T., Lovisolo, C., Schubert, A., \& Kaldenhoff, R. (2002). PIP1 plasma membrane aquaporins in tobacco, from cellular effects to function in plants. The Plant Cell, 14, 869-876.

Simpson, A. J., Reinach, F. C., Arruda, P., et al. (2000). The genome sequence of the plant pathogen Xylella fastidiosa. The Xylella fastidiosa Consortium of the organization for nucleotide sequencing and analysis. Nature, 406, 151157.

Targon, M. L. P. N., Takita, M. A., Amaral, A. M., Souza, A. A., Locali, E. C., Dorta, S. O., et al. (2007). CITEST libraries. Genetics and Molecular Biology, 30, 1019-1023.

Tyerman, S. D., Niemietz, C. M., \& Bramley, H. (2002). Plant aquaporins, multifunctional water and solute channels with expanding roles. Plant, Cell \& Environment, 25, 173-194.

Ueno, B., \& Leite, J. R. P. (1996). Estudo da variabilidade de isolados de Xylella fastidiosa obtidos de cafeeiro e citros através da análise de proteínas totais. Fitopatologia Brasileira, 21, 341.

Vieira, L., Andrade, A., Colombo, C., Moraes, A., Mehta, A., et al. (2006). Brazilian coffee genome project, an EST-based genomic resource. Brazilian Journal of Plant Physiology, $18,95-108$.

Yamada, S., Komori, T., Myers, P. N., Kuwata, S., Kubo, T., \& Imaseki, H. (1997). Expression of plasma membrane water channel genes under water stress in Nicotiana excelsior. Plant \& Cell Physiology, 38, 1226-1231. 